\title{
Predictive Control in Irrigation Canal Operation
}

\author{
Victor M. Ruiz C. and Javier Ramirez L. \\ Riego y Drenaje, Instituto Mexicano de Tecnología del Agua, Paseo Cuauhanahuac 8532, \\ Jiutepec Mor.62550, Mexico, Email: vmruiz@tlaloc.imta.mx
}

\begin{abstract}
ABS'IRAC'T
Open canal dynamics in which a constant water level is kept at the bottom end of each canal pools by the upstream control structure of the pool are characterized by a time-varying delay associated with water transport. Predictive control, based on the output prediction over a long time horizon and the minimization of a quadratic cost function is slightly sensitive to the magnitude and variation of the delay. The predictive control performance is tested on the lateral canal $\mathrm{MW}$ of the Maricopa Stanfield Irrigation and Drainage District. The simulation results illustrate the capacity of predictive control to improve canal operation.
\end{abstract}

\section{INTRODUCTION}

Water is rapidly becoming the limiting factor for development. The marked competition between municipalities, industry and agriculture is pushing toward more efficient use of this limited natural resource. Agriculture, the largest water consumer, has adopted modernization programs based on new technologies to provide more reliable and flexible water delivery to farmers. Improved irrigation service will lead to high on-farm irrigation efficiency, and less spillage and loss within the conveyance system. These factors will definitely decrease the water volume required at the source. The actors involved in water distribution must upgrade their service to improve water use efficiency. New service policies involve more complex delivery schedules, continuous changes in flow rate and duration. These factors may surpass canal operation staff capacity, in which case control theory can offer some alternatives to help accomplish the service objectives

Often, irrigation canal design considers that the turnouts in the canal pools are located very close to the downstream gate, the flow rate through the turnouts is governed by an orifice flow equation and upstream distributed control [1]. Under these conditions, the level at the downstream end of each pool (constant downstream depth pool operation method [1]) is kept constant by the gate at that point. This design solution reduces construction costs but limits irrigation service if operation is not considered during the design step. In this case, the canal delivery schedule is supply-oriented [1]: upstream control transfers the upstream water supply to a downstream point of diversion. The control strategy can produce shortages or spillage if the water requirements are not well programmed and canal management is not sufficiently flexible for modern farm irrigation needs.

For the canal designed with the above concepts, operation could be improved using downstream control. The upstream gate in each pool regulates the water depth at the downstream end. With this control, the water delivery schedule is defined by the turnout demands. The flow adjustments are made from downstream turnouts to the upstream water supply source, the natural sense for a water delivery system. This is a demandoriented system [1].

The performance of downstream control is a function of the canal capacity, that should be able to accommodate the water fluctuations introduced by the unexpected changes in the demand until the required water to satisfy them arrives from the source. Canals designed for upstream control and constant downstream depth pool operation method were designed with reduced capacity. High performance feedback and feedforward regulators are required to reduce these service limitations.

The dynamics of an irrigation canal, when a downstream control method is used to regulate the water depth at the downstream end of the pools, are characterized by long timevarying delays and time-varying process dynamics. The delay is associated with the time required for the water to travel downstream from the control structure to the point where the water depth is regulated. The delay is a function of the flow, which changes with the irrigation season and service given. This characteristic makes canal control difficult. Predictive control has shown robustness to long time delays and process dynamics that change with the operating conditions [2]. This motivated researchers to use it in canal operation.

The objective of predictive control is to drive the future process outputs "close" to their reference profile over a finite time horizon bearing in mind the control activity required to do so. This is done using a receding approach. The three fundamental components of a predictive controller are the control model, the future process output predictions and criteria minimization to determine the control action.

The performance of predictive control is based on the ability of the control model to reproduce process dynamics. Different control models have been used in canal control, including the CARIMA $[3,4,5]$, the state space [6] and the knowledge-based models [7]. Ready and Babu [8] found that by using a minimum variance controller, a particular case of predictive 
control, and a CARIMA model where the upstream water depth in the pool is introduced as a known disturbance (feedforwad), the closed loop performance was better than that obtained with an optimal regulator based on the estimated state-space feedback. Many papers report the experience of predictive control on a single pool canal; very few analyze the regulation of a multi-pool canal. Another problem of canal control is the cross-coupling effects that can not be neglected, making a multivariable solution for canal control necessary.

In this paper, a multivariable GPC was implemented using a distributed form. The predictive control is tested on the first three pools of the lateral canal WM of the Maricopa Stanfield Irrigation and Drainage district. These conditions correspond to the test case proposed by the American Society of Civil Engineering (ASCE) task committee on canal automation algorithms for control algorithm evaluation [9].

\section{PROCESS MODEL}

The evolution of water depth and flow rate in open canals is described by a set of nonlinear coupled hyperbolic partial differential equations (Saint Venant):

$$
\begin{aligned}
& \mathrm{T} \frac{\partial \mathrm{y}(\mathrm{x}, \mathrm{t})}{\partial \mathrm{t}}+\frac{\partial \mathrm{Q}(\mathrm{x}, \mathrm{t})}{\partial \mathrm{x}}=0 \\
& \frac{\partial \mathrm{Q}(\mathrm{x}, \mathrm{t})}{\partial \mathrm{t}}+\frac{\partial \frac{\mathrm{Q}^{2}(\mathrm{x}, \mathrm{t})}{\mathrm{A}}}{\partial \mathrm{x}}+\mathrm{gA} \frac{\partial \mathrm{y}(\mathrm{x}, \mathrm{t})}{\partial \mathrm{x}}+\mathrm{gA}(\mathrm{S}-\alpha)=0
\end{aligned}
$$

in which $Q(x, t)=$ flow rate flow $\left(\mathrm{m}^{3} / \mathrm{s}\right)$ and $y(x, t)=$ water depth $(\mathrm{m})$ at location $\mathrm{x}$ and time $\mathrm{t} ; \mathrm{g}=$ acceleration of gravity $\left(\mathrm{m} / \mathrm{s}^{2}\right) ; \mathrm{T}=$ flow top width $(\mathrm{m}) ; \mathrm{S}=$ friction slope; $\alpha=$ canalbed slope; $A=$ cross-sectional area of flow $\left(\mathrm{m}^{2}\right)$.

The boundary conditions associated with the canal are described by the weir or orifice equation whose general form is $Q=\mu H^{n}$, where $\mu$ is a function of the acceleration due to gravity, width of the orifice or length of the weir and a time varying discharge coefficient; $\mathrm{H}=$ head lost or head over the weir $(\mathrm{m}) ; \mathrm{n}$ is a function of the hydraulic and physical conditions presented at the boundary, and can assume a value of $n=0.5$ for the orifice and 1.5 for the weir.

Canal evolution is simulated using the SIC model based on the Preissmann implicit scheme.

\section{GENERALIZED PREDICTIVE CONTROL}

Generalized predictive control (GPC) [2] can be divided in: control model, predictions of the future process outputs, and optimization criteria to determine the required control action.

\section{Control Model}

The control model used is a discrete polynomial model, that can be written as:

$$
A\left(q^{-1}\right) y(k)=B\left(q^{-1}\right) u(k-d u)+\frac{\xi(k)}{\Delta\left(q^{-1}\right)}+D\left(q^{-1}\right) v(k-d d)
$$

where:

$A\left(q^{-1}\right)=1+a_{1} q^{-1}+\ldots .+a_{n A} q^{-n A}$
$B\left(q^{-1}\right)=b_{0}+b_{1} q^{-1}+\ldots . .+b_{n B} q^{-n B}$
$D\left(q^{-1}\right)=d_{0}+d_{1} q^{-1}+\ldots+d_{n D} q^{-n D}$

$$
\begin{aligned}
& \mathrm{B}\left(\mathrm{q}^{-1}\right)=\mathrm{b}_{0}+\mathrm{b}_{1} \mathrm{q}^{-1}+\ldots . .+\mathrm{b}_{\mathrm{nB}} \mathrm{q}^{-\mathrm{nB}} \\
& \mathrm{D}\left(\mathrm{q}^{-1}\right)=\mathrm{d}_{0}+\mathrm{d}_{1} \mathrm{q}^{-1}+\ldots+\mathrm{d}_{\mathrm{nD}} \mathrm{q}^{-\mathrm{nD}}
\end{aligned}
$$

$y(k)$ : the controlled variable (water level at the downstream end of the pool)

$u(k)$ : the control variable (flow at the upstream pool gate)

$v(k)$ : the measured perturbation (flow at the dowristream pool gate)

du, dd : time delay associated with the input and perturbation

$\Delta\left(q^{-1}\right)=1-q^{-1} ; q^{-1}:$ delay opcrator $\left(x(k-1)=q^{-1} x(k)\right)$

$\xi(\mathbf{k})$ : sequence of random variables

$\mathrm{k}$ : integer number used to denote the present sample time

\section{Prediction process}

Two possibilities are considered to determine the future process outputs. The first one is based on the Diophantine equations [2]. This method is useful for stability analysis, determination of the RST polynomial form of the control law, and the poles and zeros of the closed loop control modcl [10]. The other method, applied by Favier [11], uses the concatenation property of the optimal one-step-ahead predictor [12]. The first alternative based on the Diophantine equations is described above.

For the control model (3), the j-step a head predictor of $y(k)$, denoted by $\hat{y}_{k+j}$, is determined considering two Diophantine polynomial equations :

$$
\begin{aligned}
F\left(q^{-1}\right)=G\left(q^{-1}\right) A\left(q^{-1}\right) \Delta\left(q^{-1}\right) S_{j}\left(q^{-1}\right)+q^{-j} R\left(q^{-1}\right) & \\
S_{j}\left(q^{-1}\right) G\left(q^{-1}\right) B\left(q^{-1}\right)= & F\left(q^{-1}\right) M_{j-d u+1}\left(q^{-1}\right)+ \\
& q^{-j+d u-1} K_{j-d u+1}\left(q^{-1}\right)
\end{aligned}
$$

where $F\left(q^{-1}\right)$ and $G\left(q^{-1}\right)$ are polynomials of order $n f$ and $n g$ respectively, used to specify an "approximate model following $G\left(q^{-1}\right) / F\left(q^{-1}\right)$ " [2]. $\quad S_{j}\left(q^{-1}\right), \quad R\left(q^{-1}\right), \quad M_{j-d u+1}$, $\mathrm{K}_{\mathrm{j}-\mathrm{du}+1}$ are polynomials of order $\mathrm{j}-1, \max (\mathrm{ng}+\mathrm{na}+\mathrm{n} \Delta-1, \mathrm{nf}-$ j), j-du, and max (nf-1, nb-ng-du-2).

The optimal j-step a head predictor, $\hat{y}_{k+j}$, is denoted by

$\hat{y}_{k+j}=M_{j-d u+1} \Delta\left(q^{-1}\right) u(k-d b+j)+\hat{y}_{k+j}^{0}$

where

$$
\begin{aligned}
\hat{y}_{k+j}^{0}= & +F^{-1}\left(K_{j-d u+1}\left(q^{-1}\right) \Delta\left(q^{-1}\right) u(k-1)+\right. \\
& \left.S_{j}\left(q^{-1}\right) G\left(q^{-1}\right) D\left(q^{-1}\right) \Delta\left(q^{-1}\right) v(k-d d+j)\right)+ \\
& R_{j}\left(q^{-1}\right) y(k)
\end{aligned}
$$


Equation (8) has two terms. $\hat{y}_{\mathrm{k}+\mathrm{j}}^{0}$ is a function of all the available data up to present time " $k$ " $(y(k+j)$ for $j \leq 0 ; u(k+j)$ for $\mathrm{j}<0$ and the measured perturbations $\mathrm{v}(\mathrm{k})$ for $\mathrm{j} \leq 0)$. The future values of this perturbation are required, if they are not known, a third Diophantine equation can be used to incorporate the known information available up to present time. The second term is a function of the present and future values of $\Delta u(k+j)$ for $j=0,1, \ldots$ unknown at present time " $k$ ":

$\hat{y}_{k+j}= \begin{cases}\hat{y}_{k+j}^{0}+\sum_{j=0}^{j-d u} m_{i} \Delta u(k+j-i-d u) & \text { if } j \geq d u \\ \hat{y}_{k+j}^{0} & \text { if } j<d u\end{cases}$

where

$$
M\left(q^{-1}\right)=m_{0}+m_{1} q^{-1}+m_{2} q^{-2}+\ldots+m_{n m} q^{-n m}
$$

\section{Optimization Criteria}

The quadratic cost criteria used to determine control action $\Delta \mathrm{u}(\mathrm{k})$ is:

$$
J=\sum_{J=N S}^{N P}\left(y_{\text {ref }}(k+j)-\hat{y}_{k+j}\right)^{2}+\sum_{J=0}^{N U-1} \lambda(j) \Delta u(k+j)^{2}
$$

where $N P=$ the maximum costing horizon; $N U=$ the control horizon; NS $=$ the minimum costing horizon; $\lambda(\mathrm{j})=$ the control-weighting sequence $;$ and $\left\{\mathrm{y}_{\mathrm{ref}}(\mathbf{k})\right\}=$ reference profile.

The control law $u(k)$ that minimizes the criteria was suggested by Clarke et al [2]:

$\Delta \mathrm{U}=\left(\mathbf{M}^{\mathrm{T}} \mathbf{M}+\lambda\right)^{-1} \mathbf{M}^{\mathrm{T}}\left(\mathrm{Y}_{\mathrm{ref}}-\hat{\mathrm{Y}}^{0}\right)$

where

$\Delta U=[\Delta u(k), \Delta u(k+1), \ldots, \Delta u(k+N U-1)]^{\mathrm{T}} \quad \operatorname{dim} \Delta U=N U$

$Y_{\text {ref }}=\left[y_{\text {ref }}(k+N S), \ldots ., y_{\text {ref }}(k+N P)\right]^{T} \quad \operatorname{dim} Y_{r e f}=N P-N S+1$

$\hat{\mathrm{Y}}^{0}=\left[\hat{\mathrm{Y}}_{\mathrm{k}+\mathrm{NS}}^{0}, \ldots . ., \hat{\mathrm{Y}}_{\mathrm{k}+\mathrm{NP}}^{0}\right] \quad \operatorname{dim} \hat{\mathrm{Y}}^{0}=\mathrm{NP}-\mathrm{NS}+1$

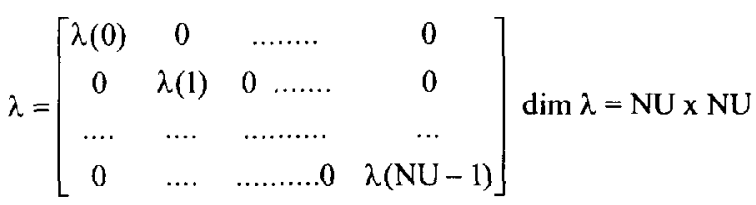

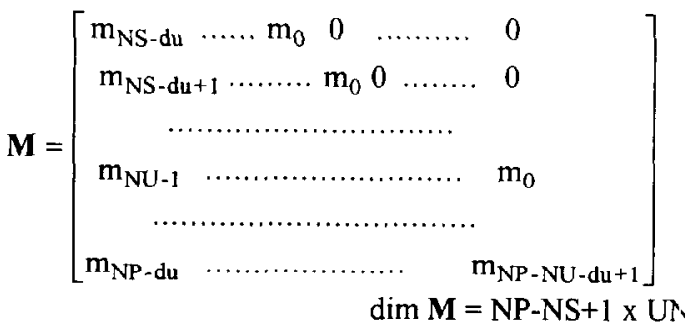

A recursive stable numerical algorithm to invert the matrix $\left(\mathbf{M}^{\mathrm{T}} \mathbf{M}+\lambda\right)$ was proposed by Favier [11]. Only the first row of the inverse matrix is required to determine $u(k)$.

The control law can be written in a RST polynomial form

$$
\begin{gathered}
\mathbf{S}(\mathrm{q}-1) \Delta(\mathrm{q}-1) \mathrm{u}(\mathrm{k})=\mathbf{T}(\mathrm{q}-1) \operatorname{yref}(\mathrm{k})-\mathbf{K}(\mathrm{q}-1) \mathrm{y}(\mathrm{k})- \\
\mathbf{F F}(\mathrm{q}-1) \Delta(\mathrm{q}-1) \mathrm{v}(\mathrm{k})
\end{gathered}
$$

where

$$
\begin{aligned}
& \mathbf{S}\left(q^{-1}\right)=F\left(q^{-1}\right)+\sum_{j=1}^{N P-N S+1} \gamma_{1, j} K_{j+N S+d u}\left(q^{-1}\right) \\
& \mathbf{T}\left(q^{-1}\right)=F\left(q^{-1}\right) \sum_{j=1}^{N P-N S+1} \gamma_{1 j} q^{+j+N S-1} \\
& \mathbf{F F}\left(q^{-1}\right)=G\left(q^{-1}\right) \sum_{j=1}^{N P-N S+1} \gamma_{1, j} q^{-d d+j+N S-1} \\
& \mathbf{R}(q-1)=\sum_{j-1}^{N P-N S+1} \gamma_{1 j} R_{j+N S-1}
\end{aligned}
$$

where

$$
\gamma=\left[\mathbf{M}^{\mathrm{T}} \mathbf{M}+\lambda\right]^{-1} \mathbf{M}
$$

\section{APPLICATION TO THE MW CANAL}

The GPC was used in simulated operations of the first three pools of the lateral MW of the Maricopa Stanfield Irrigation and Drainage District. The hydraulic and physical characteristics of the simulated pools are summarized in Table 1. In the simulation presented, the outflows were considered constant, driven by a pump station. The predictive control was evaluated in the scenario presented in Table 2 . Only the regulation capacity of the GPC was analyzed. All the offtakes changes are considered unscheduled.

Prior to on-line control of the canal, simulation studies were carried out to assess modeling and control requirements. Considering the fast responses of the first and third pool, the sampling period was set to 1 minute. The control variables was the flow rate and the controlled variable, used to satisfy the operation requirement, was the water level at the downstream end of the pools. The measurable perturbation 
considered was the flow rate at the downstream gate of each pool.

The process control models were identified in open-loop adding a PRBS signal to the operating conditions. The polynomials for the proposed model (3) were:

$$
\text { Pool 1: } \begin{aligned}
A\left(q^{-1}\right) & =1-0.3035 q^{-1}-0.5078 q^{-2}-0.018866 q^{-3} \\
B\left(q^{-1}\right) & =0.09818+0.11759 q^{-1}-0.01292 q^{-2} ; d u=1 \\
D\left(q^{-1}\right) & =-0.10230-0.05236 q^{-1}-0.05025 q^{-2} ; d d=1
\end{aligned}
$$

Pool 2: $\quad A\left(q^{-1}\right)=1-0.5275 q^{-1}-0.4724 q^{-2}$

$$
\begin{aligned}
& \mathrm{B}\left(\mathrm{q}^{-1}\right)= 0.01292+0.0172 \mathrm{q}^{-1}+0.02849 \mathrm{q}^{-2}+ \\
& 0.02365 \mathrm{q}^{-3} ; \mathrm{du}=6 \\
& \mathrm{D}\left(\mathrm{q}^{-1}\right)=-0.17726+0.02251 \mathrm{q}^{-1}+0.04412 \mathrm{q}^{-2} ; \\
& \mathrm{dd}=1
\end{aligned}
$$

Pool 3: $\quad A\left(q^{-1}\right)=1-1 q^{-1}$

$$
\begin{aligned}
\mathrm{B}\left(\mathrm{q}^{-1}\right)= & 0.03588+0.02092 \mathrm{q}^{-1}-0.05680 \mathrm{q}^{-3} \\
\mathrm{du}=2 &
\end{aligned}
$$

In all the cases $\Delta\left(q^{-1}\right)=1-q^{-1}$. It allows the introduction of an integral action into the control law. As observed in other applications, the process dynamics, with the selected control and controlled variables, are characterized by an integrator. The pools responded like tanks.

The multivariable GPC was implemented in a distributed form where each pool had an independent regulator. To reduce the interaction, the control action was propagated to the upstream pools and the flow rate was taken as a control variable. The control action applied to the pool had two components, one determined by the local GPC regulator, other the control action of the downstream pools. The control parameters were taken as NP $=10+\mathrm{du}$; NS $=\mathrm{du}$; and $\lambda=0$ in all cases. As the pools' responses are different it is not possible to fix, a priori, the closed loop response of the systems with NP, NS and $\lambda$. To partially determine the closed loop response, the polynomial of the "approximate following model" $\left(\mathrm{G}\left(\mathrm{q}^{-1}\right)\right.$ $/ F\left(q^{-1}\right)$ for pool 1 was $0.1 /\left(1-0.9 q^{-1}\right)$; for pool $20.05 /(1$ $\left.0.95 \mathrm{q}^{-1}\right)$ and for pool $30.15 /\left(1-0.85 \mathrm{q}^{-1}\right)$. The advantage of the approximate following model was seen during the simulation. A dead band of $0.015 \mathrm{~m}$ was taken for the water level GPC regulator. The flow rate at each control structure was adjusted using a local PI regulator with dead band of 25 l/s.

The evolution of the water depth at the downstream end of the pools, the flow rate and the gate opening at the control structures are shown in Fig. 1. We can observe how the predictive control is able to properly drive the canal for the proposed scenario after some fluctuations. The selected type of turnouts (pumps) saturated of the control actions for some following models analyzed.

The performance indicators [9] MAE (maximum absolute error), IAE (integral of absolute magnitude of error), StE (steady state error), IAW (integrated average absolute gate movement) and IAQ (integrated average discharge change) defined by the ASCE task committee on canal automation algorithms are given in Table 3 for the result presiented in Fig. 1
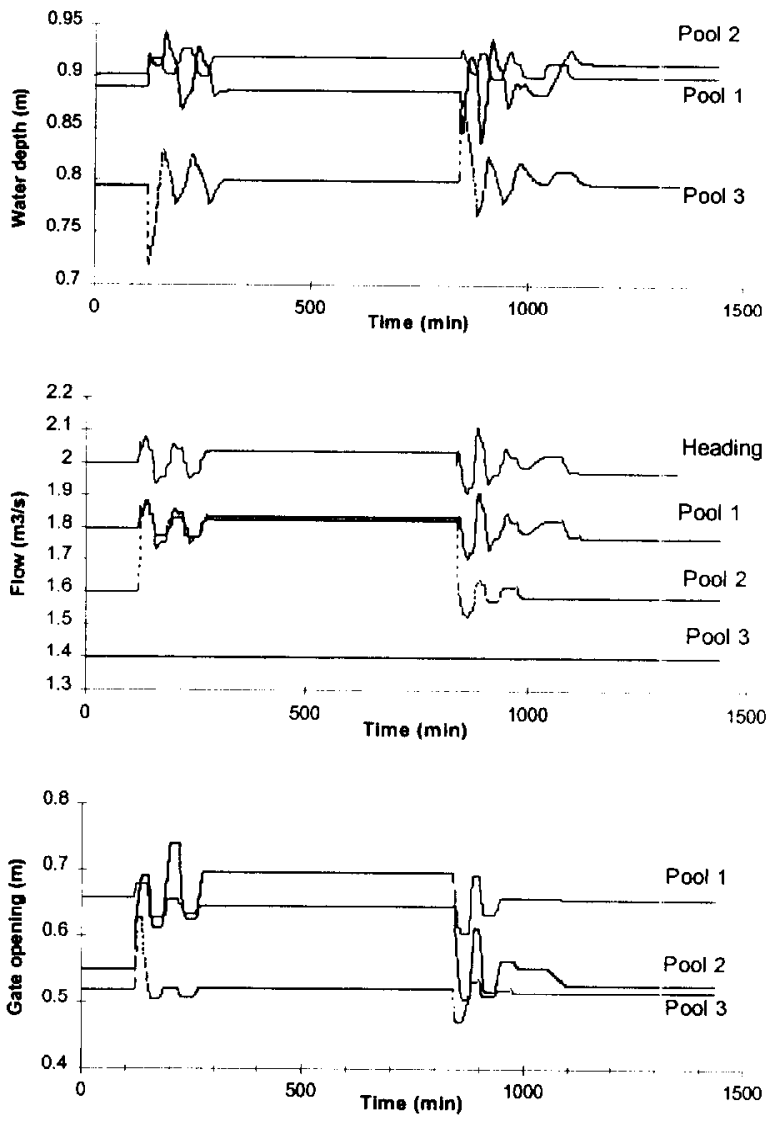

Figure 1 Simulation results: (a) Water depth at the downstream end of the pools, (b) Flow rate at the heading and downstream gate of the pools. (c) Opening of the dow'nstream gate of the pools.

\section{CONCLUSIONS}

The results presented in this paper show the GPC's performance in driving the operation of open canals. The use of other following model alternatives to prevent the saturation of the control actions (no water available) and obtain the desired closed loop response (without fluctuations) should be analyzed. A procedure to determine the control design parameter as a function of the physical and hydraulic characteristics of the canal are as yet needed.

A stability analysis and scenarios for complete operation conditions must be evaluated to determine the use of a control algorithm to drive a canal. If the performance of the GPC degrades with variations in the operation conditions, GPC could be combined with a robust identification algor thm for an adaptive implementation.

The simulation results obtained with the distributed multivariable GPC show the necessity of studying a full multivariable form of the GPC to consider the cross coupling 
effects and prevent the saturation of the control actions. In this case, the perturbation compensations are not only considered through the upstream propagation of the control action, they are also considered in the process model and, as a consequence, in the output prediction. This application is currently under development.

\section{REFERENCES}

[1] Buyalski, C. P., D. G. Ehler, H. T. Falvey, D. C. Rogers, and E. A. Serfozo, Canal systems automation manual. Denver Col., U. S. Department of the Interior, Bureau of Reclamation. Denver, 1991.

[2] Clarke, D. W., C. Mohtadi and P. S. Tuffs. Generalized predictive control- Part I. The basic algorithms-Part II. Extensions and interpretations. Automatica, Vol. 23, No. 2, 1987 pp. 137-164.

[3]Sawadogo, S., A. K. Achaibou, J. Aguilar-Martin and F. Mora Camino. An application of adaptive predictive control to water distribution systems. Proc. IFAC ITAC 91, Singapore 1991, pp 1085-1089.

[4] Ruiz C., V. M. and K. Najim. Generalized predictive control of an irrigation canal reach. Proc. IFAC/ISHS $I^{\text {st }}$ Workshop on mathematical and control applications in agriculture and horticulture, Matsuyama, Japan, 1992.

[5] Akous, Kaoutar, A. Benhammou and P. O. Malaterre. Predictive control of an irrigation channel. Proc. of the international workshop on regulation of irrigation canals: state of the art of research and applications. Marrakech, Morocco 1997, pp. 209-214.

[6] Malaterre, P. O. and J. Rodellar. Multivariable predictive control of irrigation canals. Design and evaluation on a 2-pool modcl. Proc. of the international workshop on regulation of irrigation canals: state of the art of research and applications. Marrakech, Morocco 1997, pp. 239-248.
[7] Compas, J. M. and J. C. Pagès. Regulation by predictivc control and embedded knowledge base models. Proc. of the international workshop on regulation of irrigation canals: state of the art or research and applications. Marrakech, Morocco 1977, pp. 220-229

[8] Ready, J. Mohan and N. Saratcchandra Babu (1995). Neurocontrol of irrigation canals. Proc. first international conference water resources engineering. San Antonio, Texas, USA, pp.358-362.

[9] Clemmens, A. J., T. F. Kacerek, B. Grawitz and W. Schuurmans. Test cases for canal control algorithms, J. Irrig. and Drain Engrg., Vol. 124, No. I, Jan. /Feb. 1998, pp. 2330.

[10] Ruiz, C. V. M. Commande prédictive adaptative de procédés chimiques. Doctor Thesis, ENSIGC-INPT, Toulouse, France 1990.

[11] Favier. G. Sclf-tuning long range predictive controller, Proc. of the I0 IF IFAC world congress, Munich 1990, Germany.

[12] Goodwin G. C. and K. S. Sin. Adaptive filtering prediction and control. Prentice Hall, New York, 1984, USA.

Table 1 Hydraulic and physical characteristics of the lateral canal MW

Bottom slope $0.002 \mathrm{~m} / \mathrm{m}$ Bottom width $1 \mathrm{~m}$ $\begin{array}{lllll}\text { Manning's n } & 0.014 & \text { Side slope } & 1.5 \mathrm{~m} / \mathrm{m}\end{array}$ Drop at each gate $1 \mathrm{~m} \quad$ Gate width $1.5 \mathrm{~m}$

\begin{tabular}{|c|c|c|c|c|}
\hline Pool & $\begin{array}{c}\text { Pool } \\
\text { length } \\
(\mathrm{m})\end{array}$ & $\begin{array}{c}\text { Canal } \\
\text { depth } \\
(\mathrm{m})\end{array}$ & $\begin{array}{c}\text { Gate } \\
\text { height } \\
(\mathrm{m})\end{array}$ & $\begin{array}{c}\text { Target } \\
\text { level } \\
(\mathrm{m})\end{array}$ \\
\hline 1 & 100 & 1.1 & 1.0 & 0.9 \\
\hline 2 & 1200 & 1.1 & 1.0 & 0.9 \\
\hline 3 & 400 & 1.0 & 0.9 & 0.8 \\
\hline
\end{tabular}

Table 2 Canal scenario for control test

\begin{tabular}{|c|c|c|c|c|c|c|}
\hline & $\begin{array}{c}\text { Offtake } \\
\text { initial } \\
\text { flows } \\
\left(\mathrm{m}^{3} / \mathrm{s}\right)\end{array}$ & $\begin{array}{c}\text { Check } \\
\text { initial } \\
\text { flows } \\
\left(\mathrm{m}^{3} / \mathrm{s}\right)\end{array}$ & $\begin{array}{c}\text { Unscheduled } \\
\text { offtake } \\
\text { changes at } \\
2 \mathrm{~h}\left(\mathrm{~m}^{3} / \mathrm{s}\right)\end{array}$ & $\begin{array}{c}\text { Resulting } \\
\text { check } \\
\text { flows } \\
\left(\mathrm{m}^{3} / \mathrm{s}\right)\end{array}$ & $\begin{array}{c}\text { Unscheduled } \\
\text { offtake } \\
\text { changes at } \\
14 \mathrm{~h}\left(\mathrm{~m}^{3} / \mathrm{s}\right)\end{array}$ & $\begin{array}{c}\text { Resulting } \\
\text { check } \\
\text { flows } \\
\left(\mathrm{m}^{3} / \mathrm{s}\right)\end{array}$ \\
\hline Head & ---- & 2.0 & --- & 2.0 & ---- & 2.0 \\
\hline 1 & 0.2 & 1.8 & ---- & 1.8 & $-\cdots$ & 1.8 \\
\hline 2 & 0.2 & 1.6 & -0.2 & 1.8 & 0.2 & 1.6 \\
\hline 3 & 0.2 & 1.4 & 0.2 & 1.4 & -0.2 & 1.4 \\
\hline
\end{tabular}

Table 3 Performance indicator

\begin{tabular}{|c|c|c|c|c|c|}
\hline Pool & $\begin{array}{c}\text { MAE } \\
(\%)\end{array}$ & $\begin{array}{c}\text { IAE } \\
(\%)\end{array}$ & $\begin{array}{c}\text { StE } \\
(\%)\end{array}$ & IAQ & IAW \\
\hline $1(0-12 \mathrm{hr})$ & 3.0 & 1.6 & 2.0 & 0.56 & 0.12 \\
\hline $1(12-24 \mathrm{hr})$ & 3.0 & 0.7 & 0.06 & 0.81 & 0.20 \\
\hline $2(0-12 \mathrm{hr})$ & 4.6 & 1.5 & 1.5 & 0.56 & 0.38 \\
\hline $2(12-24 \mathrm{hr})$ & 6.9 & 1.7 & 1.5 & 0.81 & 0.30 \\
\hline $3(0-12 \mathrm{hr})$ & 10.2 & 0.6 & 0.02 & 0.32 & 0.27 \\
\hline $3(12-24 \mathrm{hr})$ & 9.7 & 0.8 & 0.3 & 0.30 & 0.14 \\
\hline
\end{tabular}

